\title{
What professional activities do general practitioners find most meaningful? Cross sectional survey of Norwegian general practitioners
}

Peder Andreas Halvorsen ${ }^{1,2,6^{*}}$, Adrian Edwards ${ }^{3}$, Ivar Johannes Aaraas ${ }^{1}$, Olaf Gjerløw Aasland ${ }^{4,5}$ and Ivar Sønbø Kristiansen ${ }^{5}$

\begin{abstract}
Background: Health reforms in many countries affect the scope and nature of primary care. General Practitioners (GPs) are expected to spend more time developing public health, preventive health care, coordination of care and teamwork. We aimed to explore which professional activities GPs consider to be meaningful and how they would like to prioritise tasks.

Methods: In a cross sectional online survey 3,270 GPs were invited to consider twenty different activities in general practice. They were asked to rate each of them on a Likert scale anchored from 1 (not meaningful) to 5 (very meaningful). They then selected three activities from the item list on which they would like to spend more time and three activities on which they would like to spend less time. We used multinomial logistic regression to explore associations between the GPs' preferences for time spent on preventive health care activities and age, gender and practice characteristics.

Results: Approximately $40 \%(n=1,308)$ responded. The most meaningful activities were handling common symptoms and complaints (94\% scored 4 or 5), chronic somatic diseases (93\%), terminal care (80\%), chronic psychiatric diseases (77\%), risk conditions (76\%) and on call emergency services (70\%). In terms of priority the same items prevailed except that GPs would like to spend less time on emergency services. Items with low priority were health certificates, practice administration, meetings with local health authorities, medically unexplained symptoms, addiction medicine, follow up of people certified unfit for work, psychosocial problems, preventive health clinics for children and school health services. In multivariate regression models physician and practice characteristics explained no more than $10 \%$ of the variability in the GPs' preferences for time spent on preventive health care services.
\end{abstract}

Conclusions: The GPs found diagnosis and treatment of diseases most meaningful. Their priorities were partly at odds with those of the health authorities and policy makers.

Keywords: Health priorities, Health care reforms, General practice

\footnotetext{
* Correspondence: peder.halvorsen@kraftlaget.no

${ }^{1}$ National Centre of Rural Medicine, Department of Community Medicine,

University of Troms $\varnothing$, Troms $\varnothing$ N-9037, Norway

${ }^{2}$ General Practice Research Unit, Department of Community Medicine,

University of Tromsø, Tromsø N-9037, Norway

Full list of author information is available at the end of the article
} 


\section{Background}

Despite substantial health reforms in many countries affecting the scope and nature of primary care, little is known about the aspects of care that GPs find most meaningful and valuable for themselves and their patients. Strong primary care is frequently seen by policy-makers as essential for effective and cost-effective health care $[1,2]$. Qualities of primary care include provision of personal and personalised health care, knowledge of patients' values and preferences, and patient trust that GPs will secure the appropriate care that they need. Many health reforms seek to build on the strengths of their primary health care sectors, but also to contain secondary care costs, improve chronic disease management and increase preventive activities [3-10]. In the UK, GPs are being given unprecedented responsibility for commissioning services at regional level [6]. In Canada and the Netherlands a diverse range of primary health care reform initiatives have been implemented, including the development of primary health care teams and networks, blended payment systems, increasing the workforce and measures to improve quality and safety $[7,8]$. In Norway the Coordination Reform is currently being implemented. Coordination of care, preventive medicine and cost containment are salient priorities [5].

Primary health care reforms will necessarily involve all kinds of health personnel, but general practitioners (GPs) in particular have been expected to take on new responsibilities [5]. This, however, may come at a cost in terms of money or other activities forgone. If GPs are to use more time on preventive measures and team work, less time will be available for individual consultations with their patients. More GPs may be needed, or else current GPs may have to work more. However, it is not clear to what extent the priorities of policy-makers and the health authorities are consistent or compatible with those of the GPs themselves. If they are incongruent, the aims of primary health care reforms may be difficult to achieve.

It has been shown that Norwegian GPs spend about $70 \%$ of their total working hours on direct work with patients [11]. A majority of Norwegian GPs would prefer a shorter working week, but the proportion that perceive their workload as unacceptable is now less than $40 \%$ and decreasing [11]. In other countries it has been shown that relationships with patients [12-14], clinical competence $[12,15]$, and clinical autonomy [14] are highly valued by physicians including GPs. Conversely, some studies have identified administrative burdens, paperwork and governmental regulations as sources of dissatisfaction $[12,16]$.

What GPs would like to prioritize for themselves may not necessarily be the same as what is in their patients' best interest. Nevertheless, for health authorities, policymakers and GP leaders who wish to implement health reforms in patients' best interests, knowledge about how GPs would like to spend their time seems important. In the present study we aimed to explore what GPs might wish to prioritize among a broad range of common activities in general practice. Specifically, we asked to what extent different work activities were considered meaningful and whether GPs would like to spend more or less time on them.

\section{Methods}

In December 2009 3,270 GPs registered with the Norwegian Medical Association in Norway were sent an e-mail asking them to participate in an online survey pertinent to the forthcoming Coordination Reform [5]. We aimed to include all GPs in Norway at the time $(n=4,049$, Table 1$)$, but GPs engaged in another survey taking place at the same time were excluded. Thus a random sample comprising $81 \%$ of all Norwegian GPs were invited. The online questionnaire was administered by the Research Institute of the Norwegian Medical Association (NMA). The front screen gave a short presentation of the Coordination Reform and stated that knowledge about GPs' views about core issues pertaining to the reform was needed. Return of the online, anonymous questionnaire was considered as consent to participate in the study.

The GPs were presented with a list of twenty items covering a broad range of activities in general practice, such as handling common symptoms and complaints, follow up of chronic diseases, preventive health care, teaching, research and administrative tasks (Table 2). The GPs were asked to rate each item on a Likert scale anchored at 1 (not meaningful) and 5 (very meaningful). Subsequently, they were asked to select three activities from the list - in order of priority - on which they would like to spend more

Table 1 Respondent characteristics

\begin{tabular}{|c|c|c|}
\hline \multirow[t]{2}{*}{ Variable } & Respondents & $\begin{array}{l}\text { All Norwegian } \\
\text { GPs }\end{array}$ \\
\hline & $\mathrm{n}=1,308$ & $\mathrm{n}=4,049^{1}$ \\
\hline Age, mean & $47 y$ & $49 y^{2}$ \\
\hline Females & $36 \%$ & $35 \%{ }^{2}$ \\
\hline Specialty attainment & $66 \%$ & $55 \%^{3}$ \\
\hline $\begin{array}{l}\text { Mean number of patients listed per } \\
\text { doctor }\end{array}$ & 1,209 & $1,182^{2}$ \\
\hline \multicolumn{3}{|l|}{ Municipality, number of inhabitants } \\
\hline$<5,000$ & $13 \%$ & $14 \%{ }^{1}$ \\
\hline $5,000-9,999$ & $13 \%$ & $14 \%{ }^{1}$ \\
\hline $10,000-19,999$ & $18 \%$ & $17 \%{ }^{1}$ \\
\hline $20,000-49,999$ & $24 \%$ & $21 \%{ }^{1}$ \\
\hline $50,000+$ & $32 \%$ & $34 \%^{1}$ \\
\hline
\end{tabular}

1. Statistics Norway (www.ssb.no accessed 24th of March 2011).

2. http://www.helsedirektoratet.no/finansiering/refusjonsordninger/tall-oganalyser/Documents/hovedtallsrapport-2010.pdf.

3. http://www.legeforeningen.no/id/18 14.04.2011. 
Table 2 GPs' ratings of meaningfulness of common activities in general practice on a scale anchored from 1 (not meaningful) to 5 (very meaningful)

\begin{tabular}{lc}
\hline Activity & $\begin{array}{c}\text { Score } \mathbf{4} \text { or } \mathbf{5} \\
(\mathbf{n}=\mathbf{1 , 3 0 8})^{\mathbf{1}}\end{array}$ \\
\hline $\begin{array}{l}\text { Recent everyday symptoms and complaints } \\
\text { (e.g. infections, lumbago, tendinitis, head ache, } \\
\text { dyspnea, chest pain, abdominal pain, etc.) }\end{array}$ & $94 \%$ \\
Follow up of chronic somatic diseases & \\
(e.g. COPD, heart disease, diabetes) & $93 \%$ \\
Terminal care & $80 \%$ \\
Follow up of chronic psychiatric diseases & $77 \%$ \\
(e.g. schizophrenia, bipolar disorders, \\
anxiety/depression) \\
Risk conditions
\end{tabular}

(elevated blood pressure or cholesterol, low bone mass density)

On call emergency health care

(e.g. trauma/accidents, acute, serious somatic and psychiatric diseases)

Meetings regarding individual patients

Teaching and supervision of students and residents

Follow up of persons certified unfit for work

Psychosocial problems

(e.g. marital crises, conflicts at work)

Nursing home medicine

Quality assurance

(e.g. development and maintenance of guidelines/procedures)

Medically unexplained symptoms

(e.g. chronic fatigue, chronic pain syndroms)

Drug abuse/addiction medicine

Meetings with local health authorities

Preventive health clinics

Research

Practice administration/management

(e.g. human resource management, bookkeeping, etc.)

School health service

Health certifications

$16 \%$

1) Instead of providing a score the GPs' were also given the option to answer "not relevant to me". The number of GPs providing a score varied from 937 (school health service) to 1,304 (recent everyday symptoms and complaints).

time and three activities on which they would like to spend less time. Additionally, they were asked about preferences for practice organisation and remuneration (reported elsewhere) [17]. During the data collection period these questions raised some discussion and criticism in an internet forum for Norwegian GPs, including doubts about whether the study was independent of governmental reform interests (although it was independent). The main outcome measures were consideration of meaningfulness and priority of job tasks.

For each task we calculated the proportion of GPs who scored 4 or 5 on the meaningfulness scale. With respect to priority, we calculated proportions that would like to spend more and less time on the different tasks. For preventive health care services, nursing home medicine and following up people certified unfit for work, i.e. tasks that the health authorities expect GPs to prioritize, we tested the hypotheses that the GPs' priorities might vary by practice characteristics. We used multinominal logistic regression with GPs' preferences for time spent on the different task, i.e. less time, more time or no change, as the dependent variable. Note that "no change" in this case means that the task in question was not among the three tasks each GP was allowed to select for "less time" and "more time", respectively. Independent variables were population size of practice municipality, number of patients listed, number of GPs in the practice, specialty attainment and remuneration scheme (private practice versus salaried positions), and we adjusted for age and sex. We also considered using ordinal logistic regression, but regression diagnostics indicated that the proportional odds assumption was violated. We used SPSS version 19.0 for data analysis. $p$-values less than 0.05 were considered statistically significant. According to Norwegian law studies like ours do not require review by a research ethics committee. However, the study was approved by the Norwegian Social Science Data Services, which is the privacy ombudsman for all Norwegian universities as well as the Research Institute of the NMA. The funding source had no involvement in the conception and design of the study, the drafting of the manuscript or the decision to submit the article for publication.

\section{Results}

We obtained responses from 1,308 (40\%) of the GPs. The proportion of specialists in general practice was slightly higher among the respondents (66\%, 95\% CI 63\% to 68\%) compared to all Norwegian GPs (55\%). Otherwise the respondents were representative of Norwegian GPs with respect to age, sex, number of patients listed and population size of practice municipality (Table 1).

In terms of meaningfulness the top ranked activities were handling common symptoms and complaints, follow up of chronic diseases, terminal care, management of risk conditions such as hypertension, hypercholesterolemia and osteoporosis, and on call emergency care (Table 2). In terms of priority, the same activities prevailed except for on call emergency health care (Table 3). More than one out of four GPs would like to spend less time on health certifications, practice administration, medically unexplained symptoms, following 
Table 3 Proportions of GPs $(n=1,308)$ that would like to spend more versus less time on common activities in general practice $^{1}$

\begin{tabular}{|c|c|c|}
\hline Activity & $\begin{array}{l}\text { Would like to spend more } \\
\text { time }\end{array}$ & $\begin{array}{l}\text { Would like to spend less } \\
\text { time }\end{array}$ \\
\hline Follow up of chronic somatic diseases & $57 \%$ & $2 \%$ \\
\hline \multicolumn{3}{|l|}{ (e.g. COPD, heart disease, diabetes) } \\
\hline Recent everyday symptoms and complaints & $46 \%$ & $3 \%$ \\
\hline \multicolumn{3}{|c|}{$\begin{array}{l}\text { (e.g. infections, lumbago, tendinitis, head ache, dyspnea, chest pain, abdominal } \\
\text { pain, etc.) }\end{array}$} \\
\hline Follow up of chronic psychiatric diseases & $29 \%$ & $6 \%$ \\
\hline \multicolumn{3}{|l|}{ (e.g. schizophrenia, bipolar disorders, anxiety/depression) } \\
\hline Terminal care & $16 \%$ & $1 \%$ \\
\hline Teaching and supervision of students and residents & $17 \%$ & $2 \%$ \\
\hline Risk conditions & $22 \%$ & $8 \%$ \\
\hline \multicolumn{3}{|c|}{ (elevated blood pressure or cholesterol, low bone mass density) } \\
\hline Research & $14 \%$ & $5 \%$ \\
\hline Meetings regarding individual patients & $12 \%$ & $6 \%$ \\
\hline Nursing home medicine & $10 \%$ & $6 \%$ \\
\hline Quality assurance & $13 \%$ & $13 \%$ \\
\hline \multicolumn{3}{|l|}{ (e.g. development and maintenance of guidelines/procedures) } \\
\hline Emergency health care & $12 \%$ & $14 \%$ \\
\hline \multicolumn{3}{|c|}{ (e.g. trauma/accidents, acute, serious somatic and psychiatric diseases) } \\
\hline School health service & $2 \%$ & $10 \%$ \\
\hline Preventive health clinics & $2 \%$ & $10 \%$ \\
\hline Meetings with local health authorities & $6 \%$ & $17 \%$ \\
\hline Psychosocial problems & $7 \%$ & $19 \%$ \\
\hline \multicolumn{3}{|l|}{ (e.g. marital crises, conflicts at work) } \\
\hline Follow up of persons certified unfit for work & $8 \%$ & $27 \%$ \\
\hline Drug abuse/addiction medicine & $6 \%$ & $26 \%$ \\
\hline Medically unexplained symptoms & $5 \%$ & $28 \%$ \\
\hline \multicolumn{3}{|l|}{ (e.g. chronic fatigue, chronic pain syndroms) } \\
\hline Practice administration/management & $7 \%$ & $30 \%$ \\
\hline \multicolumn{3}{|l|}{ (e.g. human resource management, bookkeeping, etc.) } \\
\hline Health certifications & $0 \%$ & $50 \%$ \\
\hline
\end{tabular}

${ }^{1}$ Among the activities listed, the GPs chose 3 activities they would like to spend less time on and 3 activities they would like to spend more time on.

up persons certified unfit for work, and drug abuse/addiction (Table 3).

In the mulitinominal regression analyses, smaller patient lists $(<1,200)$ were associated with preferences for less time on managing risk conditions (Table 4). On the other hand, GPs with larger patient lists were less likely to prefer spending time on school health services and preventive health clinics for children and adolescents (Table 4). GPs in salaried positions tended to prefer more time for school health services. Specialists in general practice, however, were less likely to want more time in school health services (Table 4). In general GPs' preferences for time spent on preventive health care were not strongly associated with practice characteristics, and the regression models explained no more than $10 \%$ of the variability in those preferences (Table 4). Compared to older colleagues, GPs under 50 years of age were more likely to want to spend less time with those certified unfit for work (OR 1.7, CI 1.3 to 2.3). GPs with smaller patient lists (less than 1,200 ) were more likely to prefer more time for nursing home medicine (OR 1.8, CI 1.2 to 2.7), as were GPs working in smaller municipalities $(<20,000$ inhabitants, OR 1.5, CI 1.04 to 2.31$)$.

\section{Discussion}

\section{Principal findings}

GPs reported that dealing with common symptoms and complaints, chronic diseases, risk conditions, emergencies 
Table 4 Multinomial logistic regression analysis of GPs' preferences for time spent on preventive health care services ${ }^{1}$

\begin{tabular}{|c|c|c|c|c|c|c|}
\hline \multirow[b]{2}{*}{ Independent variables } & \multicolumn{2}{|c|}{ Risk conditions } & \multicolumn{2}{|c|}{ Preventive health clinics } & \multicolumn{2}{|c|}{ School health services } \\
\hline & $\begin{array}{c}\text { Less time } \\
\text { OR }(95 \% \mathrm{Cl})\end{array}$ & $\begin{array}{c}\text { More time } \\
\text { OR }(95 \% \mathrm{Cl})\end{array}$ & $\begin{array}{c}\text { Less time } \\
\text { OR }(95 \% \mathrm{Cl})\end{array}$ & $\begin{array}{c}\text { More time } \\
\text { OR }(95 \% \mathrm{Cl})\end{array}$ & $\begin{array}{c}\text { Less time } \\
\text { OR }(95 \% \mathrm{Cl})\end{array}$ & $\begin{array}{c}\text { More time } \\
\text { OR }(95 \% \mathrm{Cl})\end{array}$ \\
\hline Age 50+ & $1.0(0.6-1.6)$ & $1.1(0.8-1.5)$ & $1.3(0.8-2.0)$ & $1.5(0.6-3.8)$ & $1.4(0.9-2.1)$ & $1.8(0.6-5.5)$ \\
\hline Female & $1.0(0.6-1.5)$ & $1.3(1.0-1.7)$ & $0.8(0.6-1.3)$ & $1.0(0.5-2.2)$ & $0.6(0.4-0.9)$ & $2.0(0.8-4.7)$ \\
\hline Municipality $>20,000$ inhabitants & $1.1(0.7-1.8)$ & $0.9(0.7-1.3)$ & $1.4(0.9-2.1)$ & $0.6(0.2-1.4)$ & $1.0(0.7-1.6)$ & $0.4(0.1-1.1)$ \\
\hline Specialist in GP & $1.6(0.9-2.8)$ & $0.8(0.5-1.0)$ & $1.0(0.6-1.6)$ & $0.5(0.2-1.3)$ & $1.0(0.6-1.6)$ & $0.2(0.1-0.6)$ \\
\hline List size $<1,200$ & $1.8(1.1-2.9)$ & $0.7(0.5-1.0)^{2}$ & $0.6(0.4-0.9)$ & $1.4(0.6-3.4)$ & $0.6(0.4-0.9)$ & $2.0(0.7-5.7)$ \\
\hline$<4$ GPs in the practice & $0.6(0.3-0.9)$ & $0.8(0.6-1.1)$ & $1.4(1.0-2.1)$ & $0.7(0.3-1.6)$ & $1.0(0.7-1.5)$ & $0.6(0.2-1.4)$ \\
\hline Salaried position & $1.7(0.8-3.5)$ & $1.0(0.6-1.8)$ & $0.5(0.1-1.6)$ & $1.8(0.6-5.2)$ & $0.6(0.2-1.7)$ & $3.7(1.5-9.4)$ \\
\hline Pseudo R-Square (Nagelkerke) & \multicolumn{2}{|c|}{0.03} & \multicolumn{2}{|c|}{0.05} & \multicolumn{2}{|c|}{0.10} \\
\hline
\end{tabular}

${ }^{1}$ In the multinomial models the GPs' preferences for using less time as well as more time were contrasted to no change in the time spent on different preventive health care services.

${ }_{2} \mathrm{p}=0.026, \mathrm{Cl}$ includes 1.0 due to rounding.

and terminal care were the most meaningful tasks. Except for emergency health care, our respondents would also like to spend more time on these tasks. On the other hand, they would like to spend less time on health certifications, practice administration, meeting with local health authorities, medically unexplained symptoms, following up persons certified unfit for work, psychosocial problems, drug abuse and addiction medicine, preventive health clinics and school health services. With few exceptions, there were no strong associations between practice characteristics and GPs' preferences for time spent on preventive health care, people certified unfit for work or nursing home medicine.

\section{Strengths and weaknesses}

We are not aware of other studies regarding GPs' views on common job tasks in terms of meaningfulness and priority. The main strength is the large sample size; although the response rate (40\%) was modest, our sample encompassed $32 \%$ of all Norwegian GPs and was representative with respect to age, gender and geographical distribution. Our response rate is comparable to other online surveys, and compares favourably for surveys of busy clinicians [18]. When interpreting the results, several limitations must be borne in mind. First, our items were presented in the same order to each respondent, so we were unable to control for ordering effects. There was a statistically significant linear correlation between item order and mean scores for meaningfulness $(R=-0.6$, $p=0.004$ ), but not for priority. Second, our measures of meaningfulness and priority have not been formally tested for validity and reliability. For example, we are not able to distinguish between what GPs may prefer for themselves and what they would prefer in their patients' best interests. To the extent that these preferences differ, our findings should be interpreted with caution. Finally, even if we were able to adjust for several important physician characteristics in our analyses of group differences, the possibility of unmeasured confounders remains. In particular, the above mentioned criticism of our survey during the data collection period, and the fact that our study was carried out during a period of heated debate about the future of general practice in Norway, may have had a negative impact on the response rate, and nature of responses, and introduced bias for which we were unable to control.

\section{Relation to theories and other studies}

Various theoretical perspectives may be pertinent to our findings. For example, psychological theories emphasize factors such as individual needs, values, personality, self efficacy, goals, incentives and job characteristics as important for work motivation $[19,20]$. Economic theory assumes that individuals aim to maximise their utility (welfare, wellbeing) [21]. Empirical work indicates that for GPs, utility may depend on factors such as income [22-24], professional autonomy $[14,24,25]$, a sense of clinical competence $[12,15]$, and not least relationships with patients [13,14,22]. Our findings suggest that care for individual patients in terms of diagnosis and treatment of diseases is the most highly valued task among GPs, which seems consistent with both pertinent theories and previous studies.

\section{Implications for policy, practice and research}

With the exception of patient list size, GPs' priorities did not vary consistently by practice characteristics, specialty attainment or size of practice municipality. Proposed policy initiatives targeted at these factors per se, e.g. increasing the proportion of specialists in general practice, increasing practice size, offering more salaried positions, and merging small practices into larger ones, may not be effective in changing GPs' priorities. Policy makers may, however, note that fairly large proportions of GPs were ready to spend less time on health certifications and practice administration. 
Measures to reduce administrative burdens as well as patient list size per doctor could potentially make more time available for preventive medicine, teamwork, coordination of care and other high priority tasks.

During the past decade there has been concern, particularly in the Scandinavian countries, that an increasing emphasis on risk factor management may have undesirable consequences on doctor-patient relationships, and change clinical priorities [26,27]. It has even been claimed that GPs would prefer to spend less time on risk factors such hypertension, elevated blood cholesterol and osteoporosis [28]. In contrast, we found that risk factor management was among the top ranked items, both in terms of meaningfulness and priority. In Norway GPs typically manage patients with risk factors in their own surgery, whereas they have to leave their surgery to work in preventive health clinics, school health services and nursing homes. It is conceivable that busy clinicians - i.e. with large patient lists - are more reluctant to leave their surgeries unless the activity is perceived as meaningful. Qualitative studies might deepen our understanding of what tasks GPs find meaningful in their work and why.

It is also noteworthy that compared to younger colleagues, GPs aged 50 and above assigned relatively higher scores (in terms of priority) to follow up of persons unfit to work. We can speculate that valuing such tasks comes with experience and long term relationships with patients, or else that medical school and/or post graduate education programs do not prepare young GPs sufficiently for these tasks. Indirectly, our findings may support initiatives for extended learning periods in community settings [29].

\section{Conclusions}

Care for individual patients in terms of diagnosis and treatment was the most highly valued task among GPs in terms of meaningfulness and priority. If the GPs were to decide on their own, there would probably be less time spent on health certification, practice administration, meetings with local health authorities, medically unexplained symptoms, follow up of persons unfit for work, psychosocial problems, drug abuse and addiction medicine, preventive health clinics and school health services. These priorities are partly at odds with those of policy-makers and the health authorities. This suggests that in the patients' best interests, GPs, health authorities, patient organisations and health policymakers should engage in a respectful and meaningful dialogue.

\section{Competing interests}

The authors declare that they have no competing interests.

\section{Authors' contributions}

PAH designed the study, did the statistical analyses and drafted the manuscript. AE assisted with drafting and critical revision of the manuscript. OGA was responsible for data collection and participated in critical revision of the manuscript. IJA piloted the study and assisted with design and critical revision of the manuscript. ISK conceived of the study and assisted with design and critical revision of the manuscript. All authors read and approved the final manuscript.

\section{Acknowledgements}

The costs of data collection were covered by a grant from the Norwegian Research Council. The funding source had no role in the design, collection, analysis, or interpretation of data; in the writing of the manuscript; or in the decision to submit the manuscript for publication.

\section{Author details}

${ }^{1}$ National Centre of Rural Medicine, Department of Community Medicine, University of Tromsø, Tromsø N-9037, Norway. ${ }^{2}$ General Practice Research Unit, Department of Community Medicine, University of Troms $\varnothing$, Troms $\varnothing$ N-9037, Norway. ${ }^{3}$ Cochrane Institute of Primary Care and Public Health, School of Medicine, Cardiff University, Neuadd Meirionnydd, Heath Park, Cardiff CF14 4XN, UK. ${ }^{4}$ The Research Institute, The Norwegian Medical Association, P. box 1152 Sentrum, Oslo N-0107, Norway. ${ }^{5}$ Department of Health Management and Health Economics, Institute of Health and Society, University of Oslo, P. box 1089, Blindern, Oslo N-0318, Norway. ${ }^{6}$ Peder A. Halvorsen, Svartaksveien 15, Alta N 9516, Norway.

Received: 18 November 2012 Accepted: 18 March 2013

Published: 23 March 2013

\section{References}

1. Starfield B: Primary care: an increasingly important contributor to effectiveness, equity, and efficiency of health services. SESPAS report 2012. Gac Sanit 2012, 26(Suppl 1):20-6.

2. Starfield B, Shi L, Macinko J: Contribution of primary care to health systems and health. Milbank Q 2005, 83(3):457-502.

3. Romøren TI, Torjesen DO, Landmark B: Promoting coordination in Norwegian health care. Int J Integr Care 2011, 11:e127.

4. Willcox S, Lewis $G$, Burgers J: Issues in international health policy: strengthening primary care: recent reforms and achievements in Australia, England, and the Netherlands. Issue Brief (Commonw Fund) 2011, 27:1-19.

5. The Coordination Reform: Proper treatment - at the right place and right time. Report No. 47 To the storting. Oslo: Norwegian Ministry of Health and Care Services; 2009. Report.

6. Equity and excellence: liberating the NHS (White Paper). London: Department of Health; 2010.

7. Strumpf E, Levesque J-F, Coyle N, Hutchison B, Barnes M, Wedel RJ: Innovative and diverse strategies toward primary health care reform: lessons learned from the Canadian experience. J Am Board Fam Med 2012, 25(Suppl 1):S27-33.

8. van Weel C, Schers H, Timmermans A: Health care in the Netherlands. J Am Board Fam Med 2012, 25(Suppl 1):S12-7.

9. O'Malley AS, Tynan A, Cohen GR, Kemper N, Davis MM: Coordination of care by primary care practices: strategies, lessons and implications. Res Brief 2009, 12:1-16.

10. Goodyear-Smith F, Gauld R, Cumming J, O'Keefe B, Perth H, McCormack P: International learning on increasing the value and effectiveness of primary care (I LIVE PC) New Zealand. J Am Board Fam Med 2012, 25:S39-44.

11. Aasland OG, Rosta J: The working hours of general practitioners 20002008. Tidsskr Nor Laegeforen 2011, 131:1076-80.

12. Skolnik NS, Smith DR, Diamond J: Professional satisfaction and dissatisfaction of family physicians. J Fam Pract 1993, 37:257-63.

13. Horowitz CR, Suchman AL, Branch WT Jr, Frankel RM: What do doctors find meaningful about their work? Ann Intern Med 2003, 138:772-5.

14. Pathman DE, Williams ES, Konrad TR: Rural physician satisfaction: its sources and relationship to retention. J Rural Health 1996, 12:366-77.

15. Rivet C, Ryan B, Stewart M: Hands on: is there an association between doing procedures and job satisfaction? Can Fam Physician 2007, 53:93. 93:e.1-5, 92

16. Bovier PA, Perneger TV: Predictors of work satisfaction among physicians. Eur J Publ Health 2003, 13:299-305.

17. Halvorsen P, Steinert S, Aaraas IJ: Remuneration and organisation in general practice: Do GPs prefer private practice or salaried positions? Scand J Prim Health Care 2012, 30:229-33. 
18. Flanigan TS, Mcfarlane E, Cook S: Conducting Survey Research among Physicians and other Medical Professionals - A Review of Current Literature Importance of High Response Rates. New Orelans, LA: American Statistical Association Proceedings of the Survey Research Methods Section; 2008:4136-47.

19. Locke EA, Latham GP: What should we do about motivation theory? Six recommendations for the twenty-first century. Acad Manage Rev 2004, 29:388-403.

20. Latham GP, Pinder CC: Work motivation theory and research at the dawn of the twenty-first century. Annu Rev Psychol 2005, 56:485-516

21. Von Neumann J, Morgenstern O: Theory of games and economic behavior. 3dth edition. Princeton: Princeton University Press; 1953.

22. Walker KA, Pirotta M: What keeps Melbourne GPs satisfied in their jobs? Aust Fam Physician 2007, 36:877-80.

23. Whalley D, Gravelle H, Sibbald B: Effect of the new contract on GPs' working lives and perceptions of quality of care: a longitudinal survey. Br J Gen Pract 2008, 58:8-14.

24. Watson J, Humphrey A, Peters-Klimm F, Hamilton W: Motivation and satisfaction in GP training: a UK cross-sectional survey. $\mathrm{Br} J \mathrm{Gen}$ Pract 2011, 61:e645-9.

25. Marjoribanks T, Lewis JM: Reform and autonomy: perceptions of the Australian general practice community. Soc Sci Med 2003, 56:2229-39.

26. Getz L, Kirkengen AL, Hetlevik I, Romundstad S, Sigurdsson JA: Ethical dilemmas arising from implementation of the European guidelines on cardiovascular disease prevention in clinical practice. A descriptive epidemiological study. Scand J Prim Health Care 2004, 22:202-8.

27. Petursson H, Getz L, Sigurdsson JA, Hetlevik I: Current European guidelines for management of arterial hypertension: are they adequate for use in primary care? Modelling study based on the Norwegian HUNT 2 population. BMC Fam Pract 2009, 10:70

28. Westin S: [Medicalization without limits]. Tidsskr Nor Laegeforen 2004, 124:3179.

29. Tesson G, Hudson G, Strasser R, Hunt D (Eds): The Making of the Northern Ontario School of Medicine: A Case Study in the History of Medical Education. Montreal, QC: McGill-Queen's University Press; 2009.

doi:10.1186/1471-2296-14-41

Cite this article as: Halvorsen et al:: What professional activities do general practitioners find most meaningful? Cross sectional survey of Norwegian general practitioners. BMC Family Practice 2013 14:41.

\section{Submit your next manuscript to BioMed Central and take full advantage of:}

- Convenient online submission

- Thorough peer review

- No space constraints or color figure charges

- Immediate publication on acceptance

- Inclusion in PubMed, CAS, Scopus and Google Scholar

- Research which is freely available for redistribution

Submit your manuscript at www.biomedcentral.com/submit
(O) Biomed Central 